\title{
Implementasi Metode Vogel's Approximation Method Pada Pengoptimalan Biaya Pengiriman Barang Pada CV. Expres Nias
}

\author{
1) Eferoni Ndruru \\ STMIK Budi Darma Medan, JI. SM.Raja No.338 Sp.Limun Medan, Sumut, Indonesia \\ E-Mail: ronindruru@gmail.com
}

2) Sumiaty Adelina Hutabarat

STMIK Budi Darma Medan, JI. SM.Raja No.338 Sp.Limun Medan, Sumut, Indonesia.

E-Mail : sumiatiadelina@gmail.com

\begin{abstract}
Operations Research is one way of taking decisions in companies by formulating problems of daily life with mathematical models with the aim of getting optimal goals. Transportation problems are one of the problems in solving operational research problems with the aim of optimizing distribution costs of shipping goods from the first warehouse to the destination warehouse. Like the problem that is in $\mathrm{cv}$. Express nias where the cost of shipping goods does not calculate the optimal cost sometimes losses and profits are not optimal. The method used in solving this problem is the method of Vernel's approximation method, this method is included with the method of transportation. The results obtained in this study are that all shipping costs for cv.express nias are optimal.
\end{abstract}

Keyword :teknik riset operasional, transportasi, Vam.

\section{PENDAHULUAN}

Pengoptimalan biaya transportasi pengiriman barang merupakan salah satu masalah yang sering dihadapi dalam pendistribusian barang. salah satunya adalah dalam mengoptimalkan biaya transportasi yang akan didistribusikan pada tujuan atau lokasi yang berbeda - beda. Misalanya, ada beberapa gudang (sumber) yang masing- masing memiliki beberapa jenis barang yang sama. Jenis barang tersebut hendak dikirimkan ke satu tujuan atau lokasi yang masing-masing membutuhkan beberapa jenis barang dan memiliki kapasitas gudang atau pesediaan barang yang sudah ditentukan. Seperti yang terjadi pada PT. Express nias yang merupakan salah satu, perusahaan yang bekerja dibidang pengiriman barang masalah yang sedang dialami adalah sistem pengoptimalan biaya pengiriman barang yang mengakibat banyak kerugian. Baik dalam memaksimalkan biaya maupun meminimalkan biaya Vogel's Approximation Method (VAM). Metode ini merupakan salah satu cara penyelesaian masalah tentang Pengoptimalan biaya transportasi pengiriman barang.namun dari penyelesaian masalah tersebut, banyak yang perlu di pertimbangkan yaitu jarak, jenis barang,berat, biaya. Sehingga bisa di selesaikan dengan metode VAM.[1] Metode merupkan salah satu metode yang dari pembelajaran teknik riset operasi. [4]

Teknik riset operasi merupakan suatu teknik dalam pengambilan keputusan. Penerapan metode ini sangat menguntungkan pihak perusahaan dalam pengoptimalan biaya pendistribusian.ada beberapa peneliti sebelumnya yang menggunakan metode vam, tentang optimasi biaya distribusi beras miskin (raskin) sehingga didapat hasil yang minimum [2]. Dan juga tentang visualisasi teori optimalisasi biaya transportasi untuk pembelajaran riset operasi hasil yang didapatkan adalah biaya yang optimal.

Adapun beberapa yang membedakan biaya transportasi pengiriman barang pada CV. Express Nias salah satunya adalah letak gografis atau jarak yang berbeda. Sehingga biaya pengiriman dari suatu sumber kesuatu tujuan tidak sama, maka diperlukan sistem pengoptimalan biaya. Riset operasi merupakan pengambilan keputusan ilmiah tentang bagaimana mengoptimalkan rancangan dan operasi mesin maupun sumber daya manusia, yang biasanya terjadi pada keadaan dimana sumber daya dan alokasinya terbatas. Salah satu metode yang ada pada riset operasi adalah metode Vogel's Approximation Method (VAM) [3].

Metode Vogel's Approximation Method dapat Mengacu pada permasalahan transportasi. Maka dapat didefeniskan beberapa variabel-variabel yang digunakan 
pada penyelesain masalah transpotasi dengan metode Vogel's Approximation Method. (Dimas Bhirawa Maharisna, Mochammad Al Musadieq \& Heru Susilo).

\section{BAHAN DAN METODE)}

Teknik Riset operasi adalah peralatan manajemen yang menyatukan ilmu pengetahun, matematika, dan logika dalam rangka memecahkan masalah yang dihadapi sehari-hari sehingga dapat dipecahkan secara optimal.[4]

Masalah transportasi merupakan prosedur untuk mendapatkan dan menformulasikan biaya transportasi dengan biaya minimum pada pendistrubusian produk. Dimulai dari sumber pengiriman sampai ke tujuan. Brikut ini adalah konsep atau model masalah transportasi yang akan menggambarkan seluruh model pendistribusian [5] :

Sumber

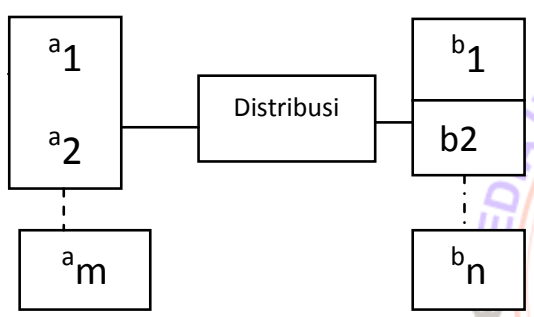

Dengan batasan :

$$
\begin{gathered}
\sum_{i=1}^{n} X_{i j} \leq a_{i} \quad ; i=1,2,3, \ldots ., m . . \\
\sum_{i=1}^{m} X_{i j} \leq b_{j} \quad ; i 1,2,3 \ldots, n \ldots \ldots \ldots(3) \\
x_{\mathrm{ij}} \leq 0 \ldots \ldots \ldots \ldots \ldots \ldots \ldots \ldots \ldots \ldots \ldots \ldots \ldots \ldots
\end{gathered}
$$

Metode Vogel's Approximation Method (VAM) dapat diartikan dengan metode heuristik merupakan evaluasi pinalti penyelesaian metode awal.[6] Pengalokasian dimulai dengan menentukan nilai selisih antara kotak dengan biaya terendah dan kotak dengan biaya terendah berikutnya untuk setiap baris dan kolom (nilai selisih disebut S). Selanjutnya dipilih baris atau kolom dengan nilai $S$ terbesar dan dilakukan pengalokasian pada kotak dengan biaya terendah pada baris atau kolom yang terpilih.[7]

\section{HASIL DAN PEMBAHASAN}

Agar lebih mudah untuk mendapatkan nilai yang optimal maka dilakukan pembentukan tabel awal. Pada data berikut ini terdiri beberapa sumber data yang didistribusi ketujuan. Yang sumbernya terdiri dari medan(md), siantar(s), tebing (t), tarurung(tr) sibolga(sb) dan tujua terdiri dari , gunung sitoli(GS), pulau telo(pt), teluk dalam(td), sirombu(Sr), lahewa(L), mandrehe $(\mathrm{mr})$. Tabel data awalnya yang digunakan dalam penyelesaian masalah ini adalah tabel pengiriman data atau distrisi barang pada PT. Nias Express . untuk lebih jelas dapat dilihat pada tabel berikut:

Kendala - kendala yang dilakukan pada masalah transportasi sebagai berikut

1. Permintaan terpenuhi

2. Sumber komoditas lebih besar dari kapasitas

Rumus penyelesaian masalah transportasi adalah sebagai berikut Minimum Z $=\sum_{i=1}^{m}$

Tabel 1 Data Awal

\begin{tabular}{|l|l|l|l|l|l|l|l|l|}
\hline TS & G.S & P.t & TD & S & L & Mr & $\begin{array}{l}\text { Kapasitas } \\
\text { (supply) }\end{array}$ \\
\hline Medan & 400.000 & 300.000 & 650.000 & 350.000 & 450.000 & 540.000 & 500.000 \\
\hline Siantar & 250.000 & 200.000 & 300.000 & 250.000 & 340.000 & 230.000 & 300.000 \\
\hline Tebing & 310.000 & 300.000 & 400.000 & 200.000 & 320.000 & 300.000 & 400.000 \\
\hline Tarutung & 200.000 & 150.000 & 250.000 & 160.000 & 250.000 & 200.000 & 310.000 \\
\hline Sibolga & 100.000 & 250.000 & 350.000 & 110.000 & 200.000 & 150.000 & 340.000 \\
\hline $\begin{array}{l}\text { Permitaan } \\
\text { (demand) }\end{array}$ & 310.000 & 500.000 & 340.000 & 300.00 & 400.000 & 500.00 & $\mathbf{2 3 4 0 . 0 0}$ \\
\hline
\end{tabular}

Dari tabel data diatas, maka dilakukan penyederhanaan tabel dengan tujuan untuk mendapatkan hasil yang optimal dengan cara, mencari perbedaan dua biaya terkecil yaitu terkecil pertama dan kedua(baris dan kolom) kemudian memilih perbedaan terbesar atau kolom selanjutnya memilih biaya terendah dan isi sebanyak mungkin dilakukan kemudian hilangkan baris dan kolom yang terisi penuh untuk tahap selanjutnya kembali kelangkah awal sampai baris dan kolom teralokasikan. Berikut penyelesaiannya : 


\begin{tabular}{|c|c|c|c|c|c|c|c|c|}
\hline Dari $^{\mathrm{Ke}}$ & G.S & P.T & T.D & S.B & L.W & MD & (Supply) & $\begin{array}{l}\text { Perbedaan } \\
\text { Baris }\end{array}$ \\
\hline Md & 400 & 300 & 650 & 350 & 450 & 540 & 500 & $350-300=50$ \\
\hline Str & 250 & 200 & 300 & 250 & 340 & 230 & 300 & $230-200=30$ \\
\hline Tbg & 310 & 300 & 400 & 200 & 220 & 300 & 490 & $220-200=20$ \\
\hline Ttg & 200 & 150 & 250 & 160 & 250 & 200 & $31 \phi$ & $160-150=10$ \\
\hline Sbg & 100 & 250 & 350 & 110 & 200 & 150 & 340 & $\begin{array}{l}110-100 \\
10\end{array}$ \\
\hline (demand) & 310 & 500 & 340 & 300 & 400 & 500 & \multirow{2}{*}{\multicolumn{2}{|c|}{$\begin{array}{l}\mathrm{Xpb}=500 \text { Hilangkan } \\
\text { baris Md }\end{array}$}} \\
\hline $\begin{array}{l}\text { Per. } \\
\text { Kolom }\end{array}$ & $\begin{array}{l}200- \\
100 \\
=100\end{array}$ & $\begin{array}{l}200- \\
150 \\
=50\end{array}$ & $\begin{array}{l}300- \\
250 \\
=50\end{array}$ & $\begin{array}{l}160- \\
110 \\
=50\end{array}$ & $\begin{array}{c}220- \\
200 \\
=20\end{array}$ & $\begin{array}{l}200- \\
150 \\
=50\end{array}$ & & \\
\hline
\end{tabular}

Selanjutnya melakukan revisi baris yang sudah terliputi garis, jika jumlah biaya terbesar terdiri beberapa kolom, maka mulai

dan seterusnya. berikut adalah revisi tabel Dengan cara dengan urutan kolom nilai terbesar pertama

1. Menghilangkan baris yang terliputi garis

Tabel 2 Revisi kolom

\begin{tabular}{|c|c|c|c|c|c|c|c|c|}
\hline${ }_{\text {Dari }}{ }^{\mathrm{Ke}}$ & G.S & P.T & T.D & S.B & L.W & MD & (Supply) & $\begin{array}{l}\text { Perbedaan } \\
\text { Baris }\end{array}$ \\
\hline Str & 250 & 200 & 300 & 250 & 340 & 230 & 300 & $230-200=30$ \\
\hline Tbg & 310 & 300 & 400 & 200 & 220 & 300 & 400 & $220-200=20$ \\
\hline Ttg & 200 & 150 & 250 & 160 & 250 & 200 & 300 & $160-150=10$ \\
\hline Sbg & 100 & 250 & 350 & 110 & 200 & 150 & 340 & $\begin{array}{l}110-100= \\
10\end{array}$ \\
\hline (dema & 3 & $50 \theta$ & 340 & 300 & 40 & 500 & & \\
\hline $\begin{array}{l}\text { Per. } \\
\text { Kolom }\end{array}$ & $\begin{array}{l}200- \\
100 \\
=100\end{array}$ & $\begin{array}{l}200- \\
150 \\
=\$ 0\end{array}$ & $\begin{array}{l}300- \\
250 \\
=50\end{array}$ & $\begin{array}{l}160- \\
110 \\
=50 \\
\end{array}$ & $\begin{array}{l}220- \\
200 \\
=20\end{array}$ & $\begin{array}{l}200- \\
150 \\
=50\end{array}$ & & $\begin{array}{l}\text { Xpb }=500 \\
\text { Hilangkan } \\
\text { kolom P.T }\end{array}$ \\
\hline
\end{tabular}

Menghilangkan Kolom yang terliputi garis Berikut ini adalah revisi baris yang masih tersisa barisnya, untuk lebih jelas dapat dilihat pada tabel berikut :

Tabel 3 Data Baris

\begin{tabular}{|c|c|c|c|c|c|c|c|}
\hline Dari $^{\mathrm{Ke}}$ & G.S & T.D & S.B & L.W & MD & (Supply) & Perbedaan Baris \\
\hline$\overline{S t r}$ & 250 & 300 & 250 & 340 & 230 & 300 & $250-230=20$ \\
\hline Tbg & 310 & 400 & 200 & 220 & 300 & 400 & $220-200=20$ \\
\hline Ttg & 200 & 250 & 160 & 250 & 200 & 300 & $200-160=40$ \\
\hline Sbg & 100 & 350 & 110 & 200 & 150 & 340 & $110-100=10$ \\
\hline (demand) & 300 & 340 & 300 & 400 & 500 & & \\
\hline $\begin{array}{l}\text { Per. } \\
\text { Kolom }\end{array}$ & $\begin{array}{l}200- \\
100 \\
=100\end{array}$ & $\begin{array}{l}300- \\
250 \\
=50\end{array}$ & $\begin{array}{l}160- \\
110 \\
=50\end{array}$ & $\begin{array}{l}220- \\
200 \\
=20\end{array}$ & $\begin{array}{l}200- \\
150 \\
=50\end{array}$ & & $\begin{array}{l}\text { Xpl }=300 \\
\text { Hilangkan baris } \\
\text { Str }\end{array}$ \\
\hline
\end{tabular}

Melakukan revisi Baris Lagi, dengan menghilangkan baris yang terliputi garis

Tabel 4. Revisi kolom

\begin{tabular}{|c|c|c|c|c|c|c|c|}
\hline $\begin{array}{l}\mathrm{Ke} \\
\text { Dari }\end{array}$ & G.S & T.D & S.B & L.W & MD & (Supply) & $\begin{array}{c}\text { Perbedaan } \\
\text { Baris }\end{array}$ \\
\hline Str & 250 & 300 & 250 & 340 & 230 & 300 & $250-230=20$ \\
\hline Tbg & 310 & 400 & 200 & 220 & 300 & 400 & $220-200=20$ \\
\hline Sbg & 100 & 350 & 110 & 200 & 150 & 340 & $110-100=10$ \\
\hline (demand) & 300 & 340 & 300 & 400 & 500 & & \\
\hline Per. & $250-$ & $350-$ & $200=$ & 220. & $230-$ & & $\mathrm{Xpb}=300$ \\
\hline Kolom & $\begin{aligned} & 100 \\
= & 150\end{aligned}$ & $\begin{array}{l}300 \\
=50\end{array}$ & $\begin{array}{l}110 \\
=90\end{array}$ & $\begin{array}{l}200 \\
=20\end{array}$ & $\begin{aligned} & 150 \\
= & 80\end{aligned}$ & & $\begin{array}{l}\text { Hilangkan } \\
\text { kolom G.S }\end{array}$ \\
\hline
\end{tabular}

Melakukan Revisi Baris yang masih belum terliputi garis.

\begin{tabular}{|c|c|c|c|c|c|c|}
\hline $\begin{array}{l}\text { Ke } \\
\text { Dari }\end{array}$ & T.D & S.B & L.W & MD & (Supply) & $\begin{array}{c}\text { Perbedaan } \\
\text { Baris }\end{array}$ \\
\hline Str & 300 & 250 & 340 & 230 & 300 & $250-230=20$ \\
\hline $\mathrm{Tbg}$ & 400 & 200 & 220 & 300 & 400 & $220-200=20$ \\
\hline Sbg & 350 & 110 & 200 & 150 & 342 & $150-110=40$ \\
\hline (demand) & 340 & 300 & 400 & 500 & & \\
\hline $\begin{array}{l}\text { Per. } \\
\text { Kolom }\end{array}$ & $\begin{array}{l}350- \\
300 \\
=50\end{array}$ & $\begin{array}{l}200- \\
110 \\
=90\end{array}$ & $\begin{array}{l}220- \\
200 \\
=20\end{array}$ & $\begin{array}{r}230- \\
150 \\
=80\end{array}$ & & $\begin{array}{c}X / p b=340 \\
\text { Hilangkan baris } \\
\text { Sbg }\end{array}$ \\
\hline
\end{tabular}

Melakukan Revisi Kolom dengan cara menghilangkan baris dan kolom yang memliki biaya terkecil.

Tabel 5. Revisi Baris 
Tabel 6 Revisi Kolom

\begin{tabular}{|c|c|c|c|c|c|c|}
\hline $\begin{array}{l}\text { Ke } \\
\text { Dari }\end{array}$ & T.D & S.B & L.W & MD & $\begin{array}{l}\text { (Sup } \\
\text { ply) }\end{array}$ & Perbedaan Baris \\
\hline Str & 300 & 250 & 340 & 230 & 300 & $250-230=20$ \\
\hline Tbg & 400 & 200 & 220 & 300 & 400 & $=20$ \\
\hline (demand & 340 & 300 & 400 & 500 & & \\
\hline $\begin{array}{c}\text { Per. } \\
\text { Kolom }\end{array}$ & $\begin{array}{r}400- \\
300 \\
=100\end{array}$ & $\begin{array}{l}250- \\
200 \\
=50\end{array}$ & $\begin{array}{l}240- \\
220 \\
=20\end{array}$ & $\begin{array}{r}300- \\
230 \\
=70\end{array}$ & & $\begin{array}{c}X p b=340 \\
\text { Hilangkan Kolom } \\
\text { S.B }\end{array}$ \\
\hline
\end{tabular}

Melanjutkan Revisi Baris yang masih tersisa

Tabel 7 Revisi Baris

\begin{tabular}{|c|c|c|c|c|c|}
\hline $\begin{array}{l}\text { Ke } \\
\text { Dari }\end{array}$ & S.B & L.W & $\mathrm{MD}$ & (Supply) & Perbedaan Baris \\
\hline Str & 250 & 340 & 230 & 300 & $250-230=20$ \\
\hline $\mathrm{Tbg}$ & 200 & 220 & 300 & 400 & $220-200=20$ \\
\hline (demand) & 300 & 400 & 500 & & \\
\hline $\begin{array}{c}\text { Per. } \\
\text { Kolom }\end{array}$ & $\begin{array}{l}250- \\
200 \\
=50\end{array}$ & $\begin{array}{l}240- \\
220 \\
=20\end{array}$ & $\begin{array}{l}300- \\
230 \\
=70\end{array}$ & & $\begin{array}{l}\text { Xpo }=300 \\
\text { Hilangkan } \\
\text { Kolom S.B }\end{array}$ \\
\hline
\end{tabular}

Dari tabel diatas, dapat dilihat pada tabel berikut sisa kolom dan baris

Tabel 8 Hasil akhir

\begin{tabular}{|c|c|c|c|c|}
\hline $\begin{array}{l}\text { Ke } \\
\text { Dari }\end{array}$ & S.B & L.W & $\overline{M D}$ & (Supply) \\
\hline Tbg & 200 & 220 & 300 & 400 \\
\hline (demand) & 300 & 400 & $\begin{array}{l}(500-300) \\
=200\end{array}$ & $\begin{array}{l}X_{T h g / S . B}=300 \\
X_{T b g / L . W}=400 \\
X_{T b g / S . B}=200\end{array}$ \\
\hline
\end{tabular}

Jadi biaya transportasi yang Optimal adalah : $(300 \times 500)+(150 \times 500)+(160 \times 300)+$ $(100 \times 300)+(110 \times 340)+(300 \times 340)+$ $(230 \times 300)+(300 \times 200)=\mathbf{5 7 1 , 4 0 0}$

(OPTIMAL)

\section{KESIMPULAN}

Dari hasil penelitian ini dapat disimpulkan bahwa:

1. Pengoptimalan biaya pengiriman barang pada PT. Nias Express lebih optimal dengan mengunakan metode VAM dibandingkan dengan dengan metode lainya .

2. Metode VAM lebih baik diimplementasikan dalam meminimumkan biaya, karena dari biaya yang begitu banyak masih dapat diminimumkan lagi dengan cara menghilangkan kolom dan baris pada tabel biaya

\section{UCAPAN TERIMAKASIH}

Ucapan terimakasih kepada Direktorat Jenderal Pendidikan Tinggi, Kementerian Pendidikan Nasional, Republik Indonesia atas bantuan dana penelitian melalui program Penelitian Unggulan Strategis Nasional (PUSNAS) 2013-2015 dan Penelitian Hibah Disertasi Doktor 2015.

\section{DAFTAR PUSTAKA}

[1] M. M. Nwc and D. A. N. Vam, "No Title," pp. 83-90, 2007.

[2] I. Pendahuluan and A. M. Transportasi, "Analisa Perbandingan Metode Vam Dan Modi Dalam Pengiriman Barang Pada Pt. Mitra Maya Indonesia," vol. 16, pp. 311-317, 2017.

[3] E. Ndruru, F. T. Waruwu, A. Yanny, K. Kunci, : Hungarian, and P. Alokasi, "KOMIK (Konferensi Nasional Teknologi Informasi dan Komputer) ALOKASI PEKERJA PADA SUATU PROYEK DENGAN METODE HUNGARIAN (STUDI KASUS: PT. IRA WIDYA UTAMA MEDAN)."

[4] A. S. Aribowo, "Visualisasi Teori Optimalisasi Biaya Transportasi Untuk Pembelajaran Riset Operasi," Semin. Nas. Inform., vol. 2008, no. semnasIF, pp. 76-83, 2008.

[5] D. B. Maharisna, M. Al Musadieq, and H. Susilo, "Analisis dan Desain Sistem Informasi Trasnportasi Dengan Metode Vogel's Approximation ( Studi Kasus pada UD . Sumber Jaya Grosir Malang )," J. Adm. Bisnis, vol. 43, no. 2, pp. 19-28, 2017.

[6] "Z:: S T'."

[7] J. Rosta and H. Tannady, "Pendistribusian Produk yang Optimal dengan Metode Transportasi," J. Tek. dan IImu Komput., vol. 1, no. 4, pp. 347-352, 2012. 